\title{
The use of Electronic Health Records to Support Population Health: A Systematic Review of the Literature
}

\author{
Clemens Scott Kruse $^{1}$ (D) $\cdot$ Anna Stein ${ }^{1} \cdot$ Heather Thomas $^{1} \cdot$ Harmander Kaur $^{1}$ \\ Received: 12 January 2018 / Accepted: 19 September 2018 / Published online: 29 September 2018 \\ (C) The Author(s) 2018
}

\begin{abstract}
Electronic health records (EHRs) have emerged among health information technology as "meaningful use" to improve the quality and efficiency of healthcare, and health disparities in population health. In other instances, they have also shown lack of interoperability, functionality and many medical errors. With proper implementation and training, are electronic health records a viable source in managing population health? The primary objective of this systematic review is to assess the relationship of electronic health records' use on population health through the identification and analysis of facilitators and barriers to its adoption for this purpose. Authors searched Cumulative Index of Nursing and Allied Health Literature (CINAHL) and MEDLINE (PubMed), 10/02/2012-10/02/2017, core clinical/academic journals, MEDLINE full text, English only, human species and evaluated the articles that were germane to our research objective. Each article was analyzed by multiple reviewers. Group members recognized common facilitators and barriers associated with EHRs effect on population health. A final list of articles was selected by the group after three consensus meetings $(n=55)$. Among a total of 26 factors identified, $63 \%(147 / 232)$ of those were facilitators and $37 \%$ (85/232) barriers. About $70 \%$ of the facilitators consisted of productivity/efficiency in EHRs occurring 33 times, increased quality and data management each occurring 19 times, surveillance occurring 17 times, and preventative care occurring 15 times. About $70 \%$ of the barriers consisted of missing data occurring 24 times, no standards (interoperability) occurring 13 times, productivity loss occurring 12 times, and technology too complex occurring 10 times. The analysis identified more facilitators than barriers to the use of the EHR to support public health. Wider adoption of the EHR and more comprehensive standards for interoperability will only enhance the ability for the EHR to support this important area of surveillance and disease prevention. This review identifies more facilitators than barriers to using the EHR to support public health, which implies a certain level of usability and acceptance to use the EHR in this manner. The public-health industry should combine their efforts with the interoperability projects to make the EHR both fully adopted and fully interoperable. This will greatly increase the availability, accuracy, and comprehensiveness of data across the country, which will enhance benchmarking and disease surveillance/prevention capabilities.
\end{abstract}

Keywords Electronic health records $($ EHR) $\cdot$ Outcomes $\cdot$ Population health $\cdot$ Public health

\section{Introduction Background}

Healthcare Information Technology (HIT) is changing how the healthcare industry operates and has already began to reduce waste and help improve health outcomes [1]. A major

This article is part of the Topical Collection on Transactional Processing Systems

Clemens Scott Kruse

scottkruse@txstate.edu

1 Texas State University, 601 University Dr, Encino 250, San Marcos, TX 78666, USA component of HIT is the Electronic Health Record (EHR). We used the definition of the EHR from the Center of Medicaid and Medicare Services (CMS): Electronic health records are digital forms of patient records that include patient information such as personal contact information, patient's medical history, allergies, test results, and treatment plan [2]. Some benefits of EHRs include improving efficiency, increasing positive patient outcomes, and population health. ${ }^{1}$ Potential improvements in population health include EHRs ability to organize and analyze a large amount of patient information. This is particularly pertinent since the Public Health Data Standards Consortium (PHDSC) and the Center for Disease Control (CDC) completed its project to standardize public 
health case reports in accordance with HL7 [3]. This project in 2012 is one example of many ongoing efforts to establish data standards in support of the public health and the EHR.

Population health is "the health outcomes of a group of individuals, including the distribution of such outcomes within a group" [4]. and EHRs provide access to public health data to survey the population for potential health improvements or act as a safety net for potential health threats. ${ }^{5}$ A new program called "DiSTRIBuTE" that uses the EHRs in the surveillance of population health issues [5], and recent use found that electronic health records were better able to track "weekly influenza trends on an ongoing basis better than and in a "more timely than manual reporting from sentinel providers" [5]. Distributed Surveillance Taskforce for Realtime Influenza Burden Tracking and Evaluation (DiSTRIBuTE), run by the International Society for Disease Surveillance (ISDS), collects aggregated data by age group to improve decision making on public safety, cost, quality, and outcomes. This distributeddata is collected, analyzed, and interpreted in real time. Privacy of information is managed by the Fair Information Practice Principles (FIPPs), and the de-identified data is shared electronically to address specific population-healthrelated questions. The CDC in 2009 to support the tracking of the H1N1 pandemic, among other examples. EHRs can provide additional screening of health records beyond surveillance that can lead to additional research [5]. Public health surveillance observes a population and brings attention to various health threats or monitors the general health of the population [6]. There is even a positive correlation between the use of EHRs by primary care providers and the ability to accurately report to public health officials [7].

Utilizing and incorporating Electronic Health Records in surveillance and care interventions can help aid the health of the population it serves. Many of these studies have shown significant positive effects of EHRs interaction with public health. Previous research shows how EHRs are being used to surveil various populations, and some review other countries' use of EHRs for surveillance [8]. Some positive effects that were observed included better surveillance of infectious diseases, improved management of patients with chronic diseases, and identify populations with higher risk factors [8]. The recent shifts in healthcare policy such as The ACA have recommended health practices to focus on preventive care to improve the overall health of the population [1]. Shih and De Leon discovered that physicians who implemented EHRs were better able to deliver recommended preventive care into their practices for low-income populations [9]. Electronic health records have been implemented to provide more coordinated and patient-centered care. EHR implementation in the ICU significantly reduces the central line associated bloodstream infections and surgical intensive care unit mortality rates [10]. EHRs provide secure access to patient information resulting in positive outcomes in relations to quality of care and productivity [11]. EHR systems have been used to manage chronic disease like diabetes, and it has been found that regular use of the EHR can reduce fragmentation of data and increase continuity of care between providers if the providers participate in health information exchanges [12]. EHRs in the emergency department (ED) improve medical decision making when using a decision tree; It increases the patient's quality of life, and it was found to be cost-effective [13]. Another cost benefit assessment for using electronic health records for data showed promising results [14]. The European Electronic Health Records for Clinical Research (EHR4CR) has developed an innovative platform that is capable of transforming traditional research processes appeared to be highly beneficial by reducing the actual person-time, operational costs, or average cycle time for Phase II-III clinical trials when compared to current practices in a pre-launch environment [14].

Other studies have illuminated possible barriers to the success of EHRs. Some of these barriers include lack of interoperability, errors in medical information, and the financial resources that are required to accommodate HIT. Medical errors may still occur despite the increase of information being gathered from patients with the use of EHR [15]. Patients who received medical and surgical care showed same outcomes in six diverse states independent of the use of EHRs. No specific benefits in patient outcomes were related to EHRs [16]. Patient satisfaction can be adversely affected by the EHR due to a decrease in attention that a physician exhibits while making notes in the system [17]. Adoption of the EHRs is not without obstacles; however, results of the research is mixed on whether a proper implementation of an EHR could improve the operations of population health.

\section{Objectives}

The purpose of this study is to review the literature previously published on the effects of EHRs on population health. Health Information Technology is becoming more widely utilized, however, the industry has still not been able to achieve its overall accessibility. It is our goal to answer whether the use of electronic health information can play a vital role in improving the health of populations, as well as identify key inhibitors to its adoption and/or key use.

\section{Methods}

The articles used for this systematic review were gathered and compiled using PubMed (MEDLINE complete) and The Cumulative Index to Nursing and Allied Health Literature (CINAHL). The search process is illustrated in Fig. 1. The United States National Library of Medicine's Medical Subject Headings (MeSH) was used to find the key terms related to our topic in PubMed. With the help of MeSH, we 
Fig. 1 Literature Search with inclusion and exclusion criteria
PubMed (MEDLINE)

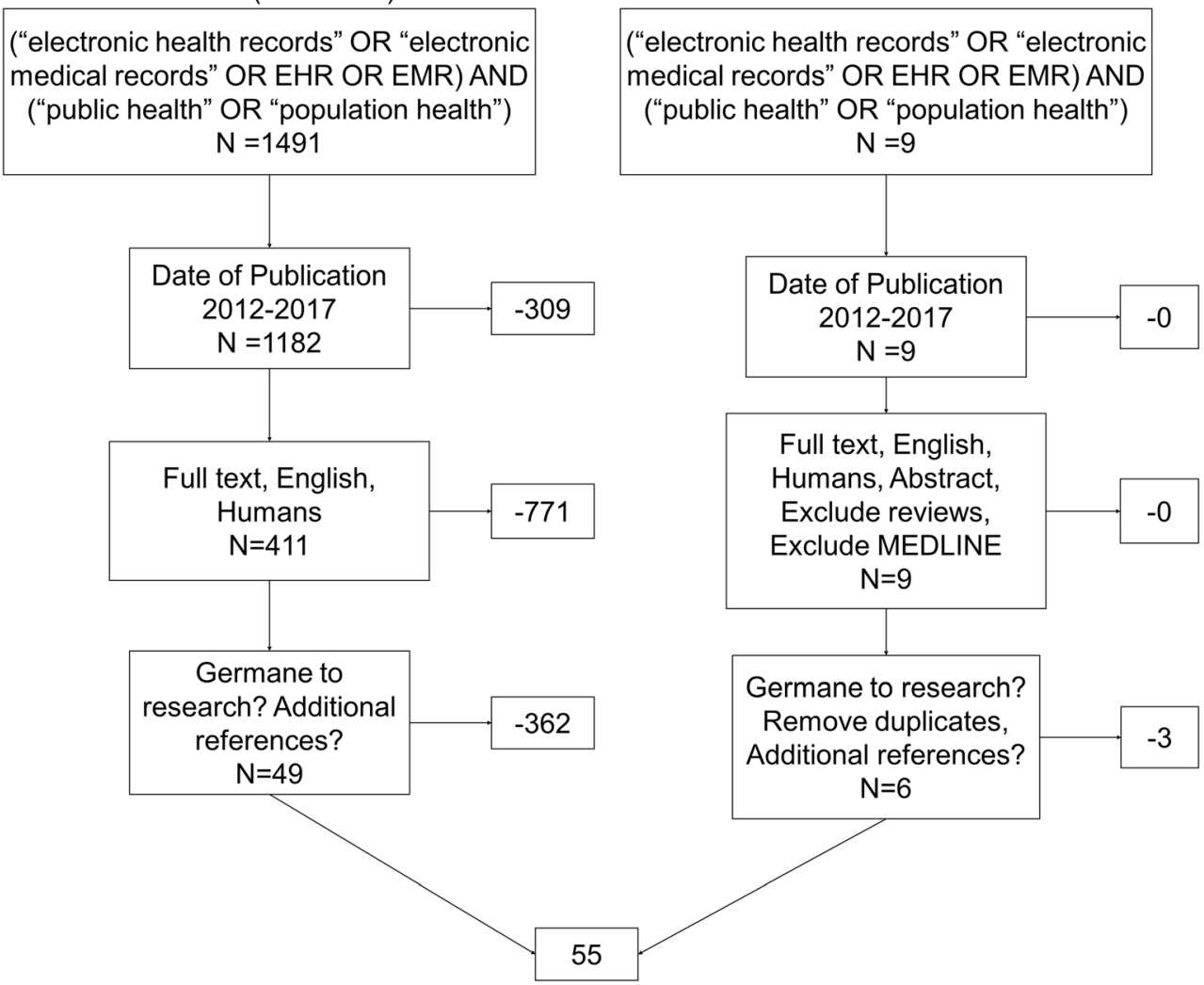

were able to identify the appropriate sub-headings under the key terms. Our final key terms in the search process for both databases were "EHR" "electronic health record" "EMR" "electronic medical record" and "population health" or "public health". While these terms have distinct definitions from each other, they are often used synonymously. We included both so that the search would be more exhaustive. In accordance with good research practice, we also included Boolean operators and quotation marks in the search string. The initial search in PubMed and CINAHL resulted in 1491 and nine items, respectively. We chose a timeframe of five years to keep the grouping small enough for reasonable analysis. After filtering relevant time frame academic journals, English only, and other peer review selection processes, we were left with 420 articles. Our process was to divide up these 420 abstracts between reviewers in a way that ensured each abstract was read by at least 2 reviewers. We independently assessed the relevance of each abstract in an Excel workbook and then combined the assessments during a consensus meeting. During this meeting we resolved any conflict in the assessments (germane or not germane to our research) to reach a final grouping of 55 articles for full analysis. A Kappa statistic of .83 was calculated, which demonstrates strong agreement among the reviewers, as well as consistency in reading and initial analysis of suitability. The same process was repeated for analysis of the articles that was used for analysis of the abstracts. Independent observations were recorded and later combined for a consensus meeting. During this second round, reviewers were also asked to pay attention to the references of each article to identify salient resources that may not have been caught by our search. This search did not result in any additional articles added to the group analyzed $(n=55)$.

During the second consensus meeting, reviewers shared their observations of facilitators and barriers to adoption of the EHR for managing public health. Through this process, reviewers categorized and grouped their observations in logical manner. An additional read of the articles took place to identify bias and limitations. These were shared in a third and final consensus meeting.

\section{Results}

The results of our analysis are listed in Table 1 . This table includes the source article, the facilitators, barriers, bias, and limitations of the articles analyzed.

We examined the work of 414 authors and co-authors who published 55 works that discuss Electronic Health Records, Population and or Public Health. We identified a total of 232 factors, which consisted of 63\% (147/232) facilitators and $37 \%$ (85/232) barriers. Utilizing EHRs resulted in a greater number of benefits than negative impacts to population health. 


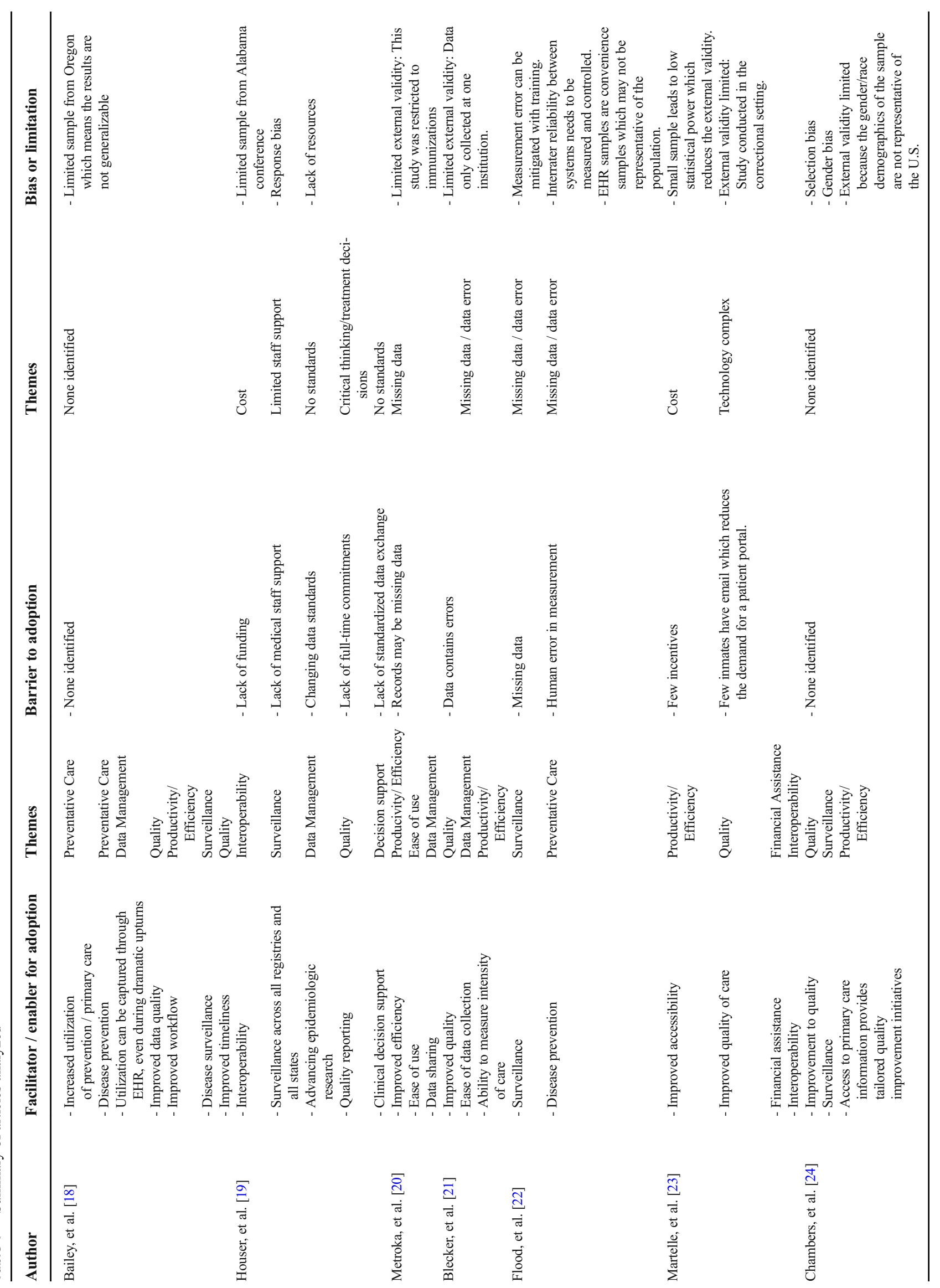




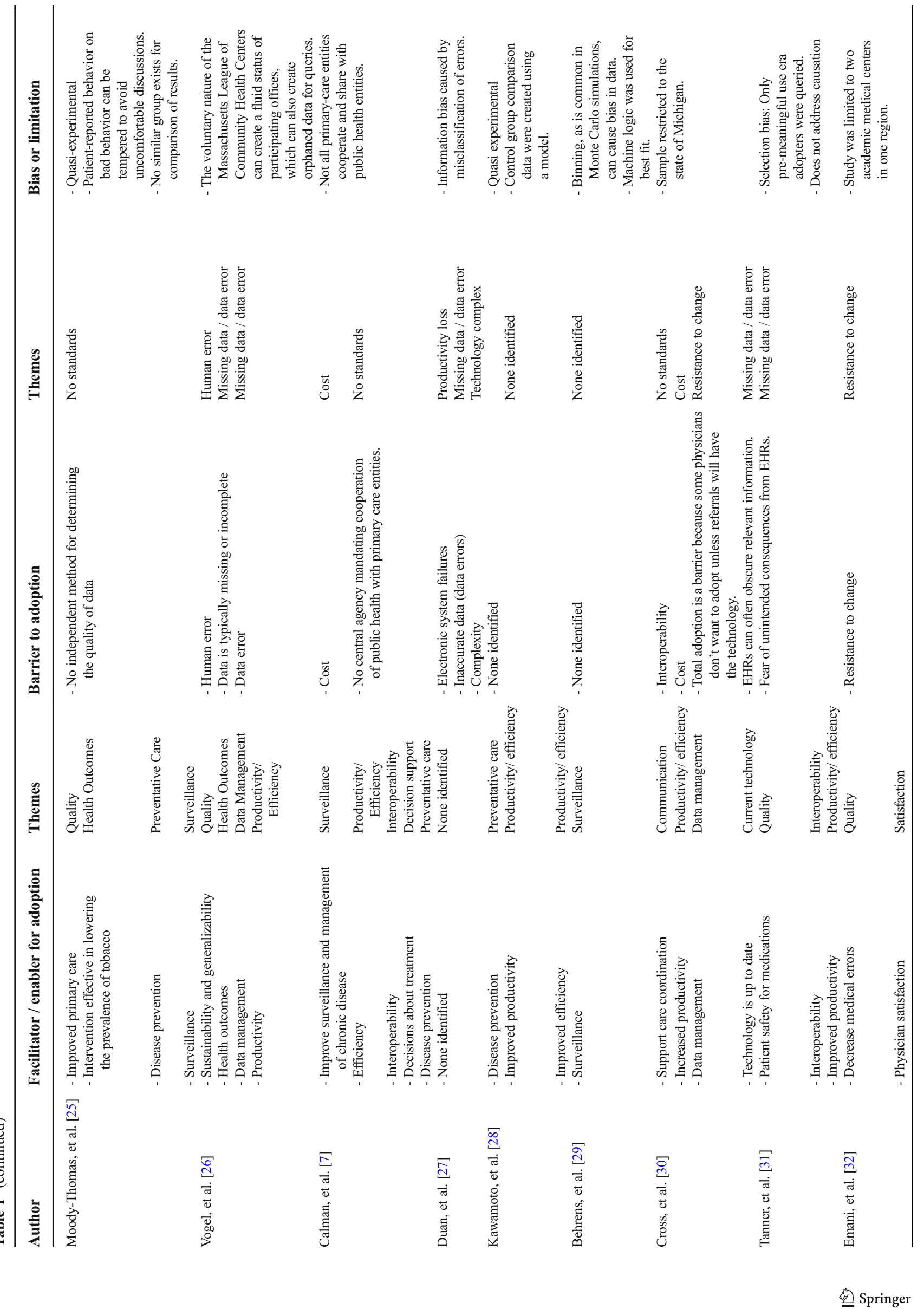




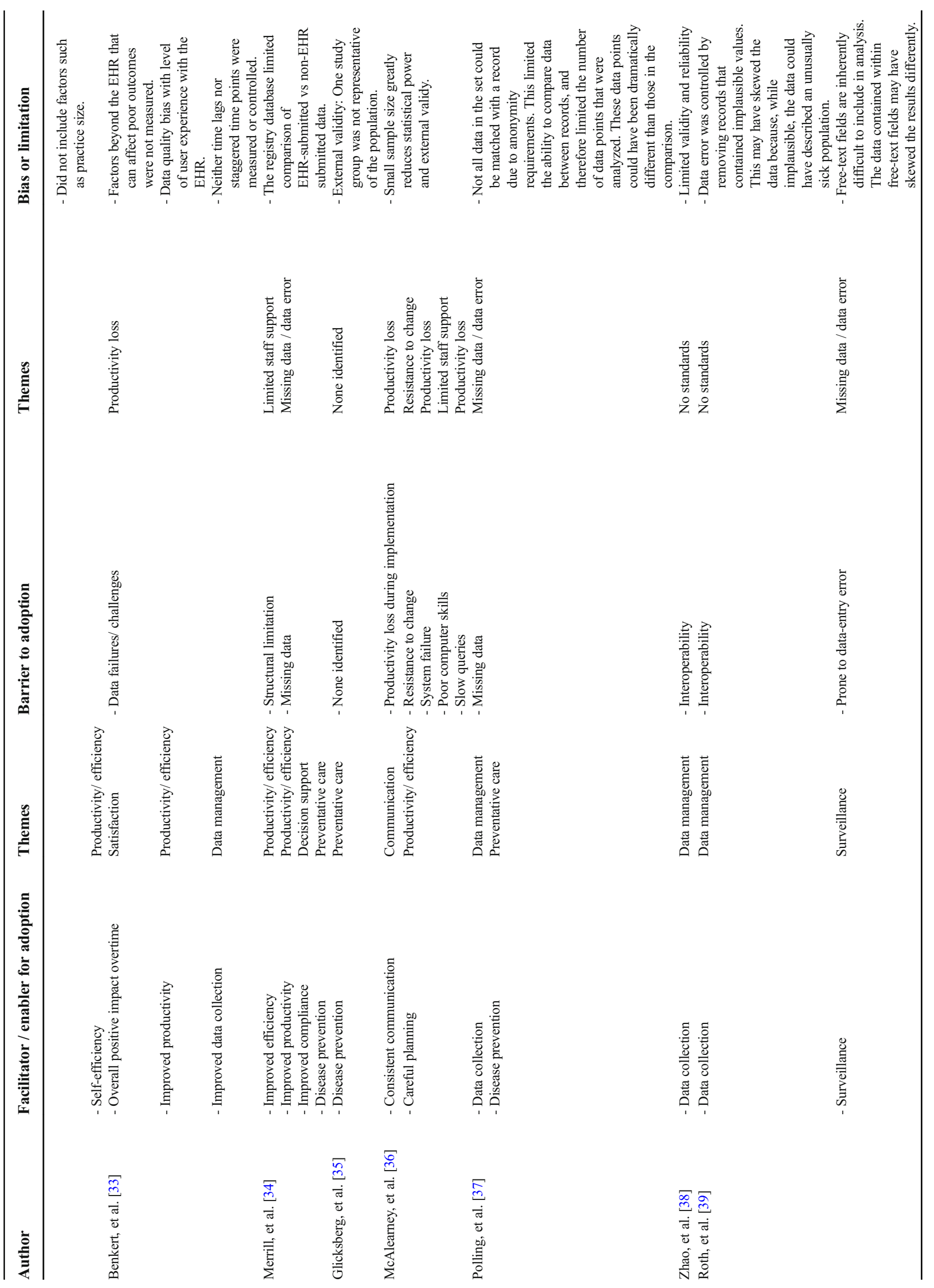




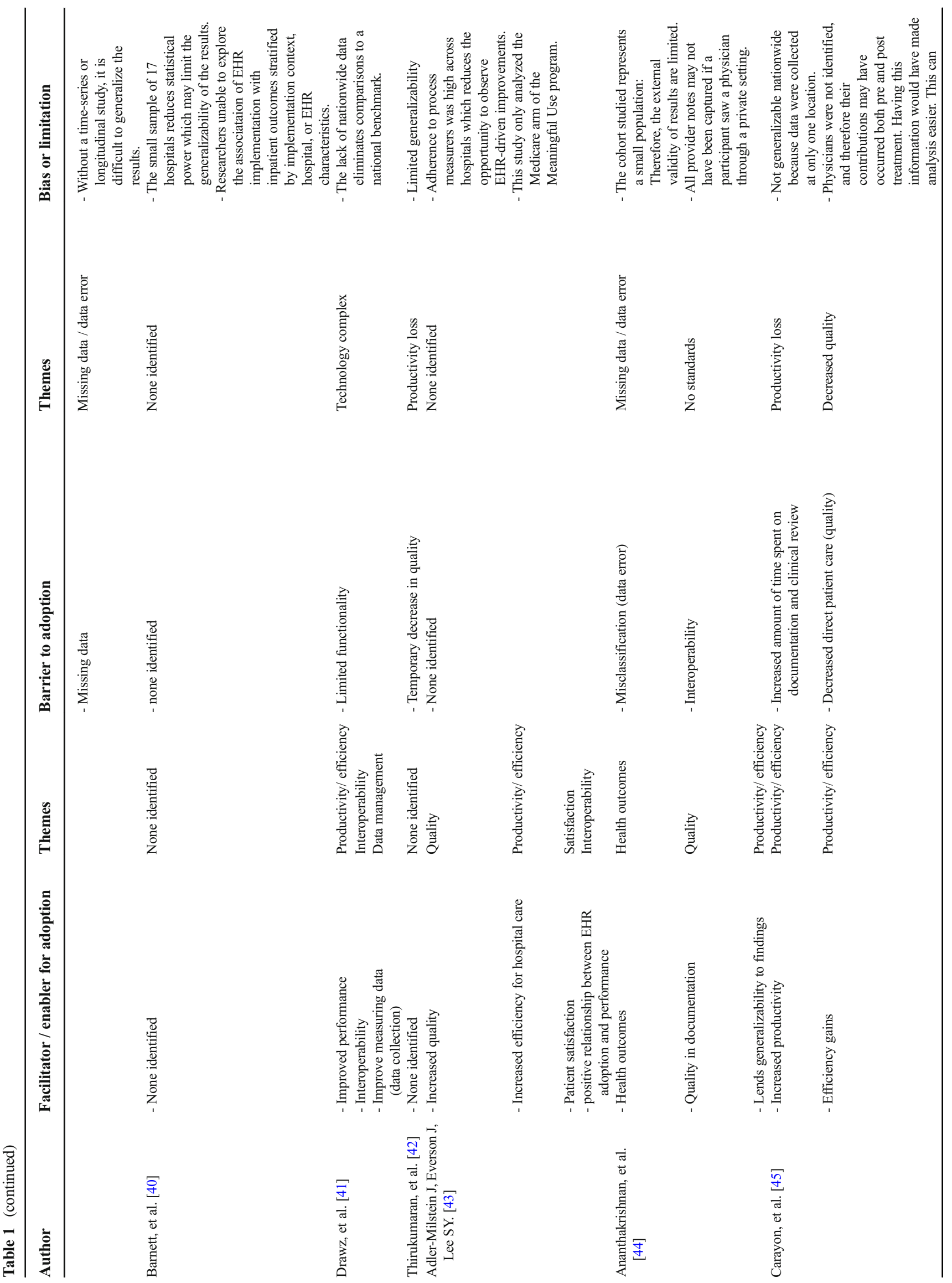




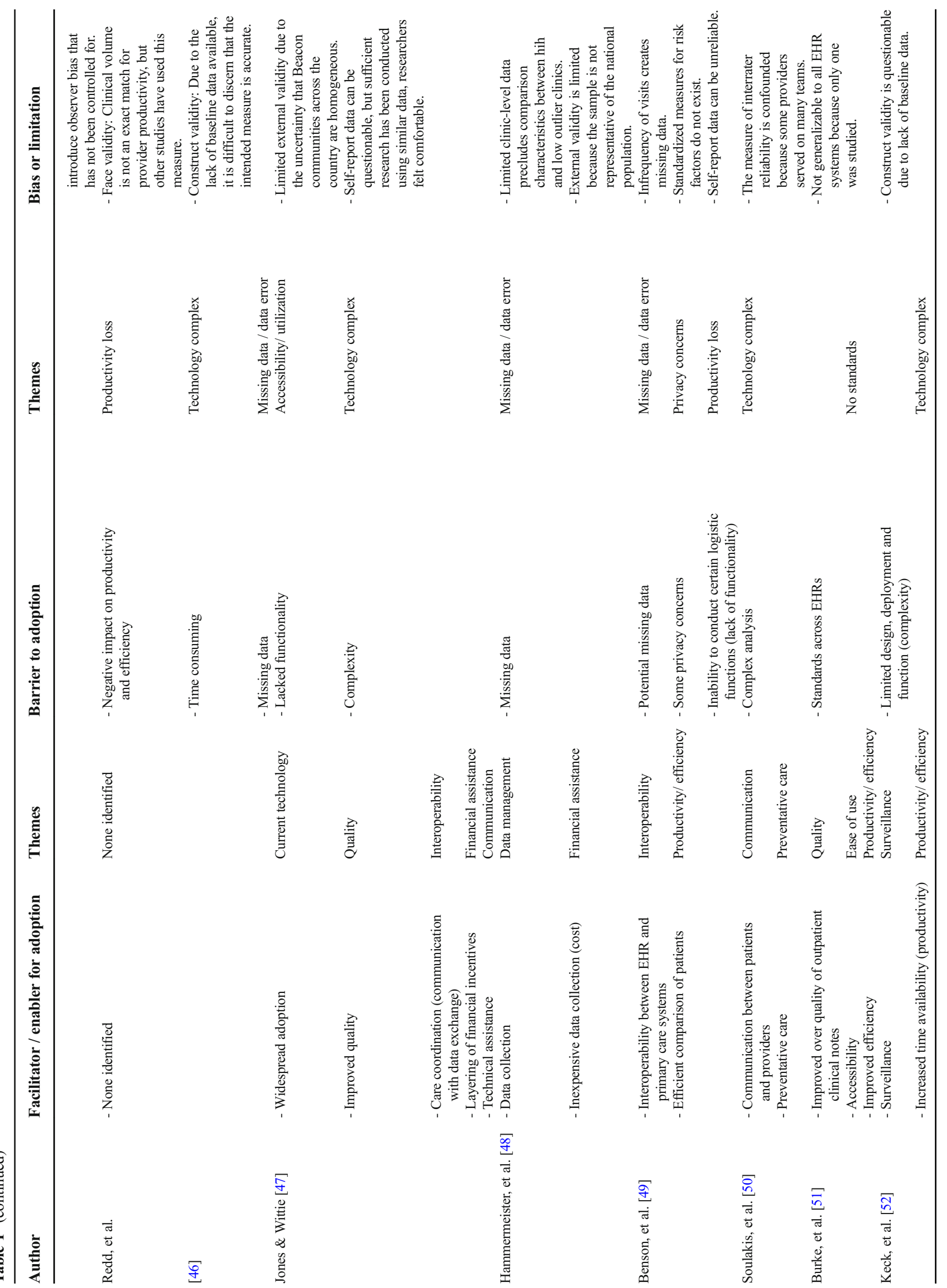




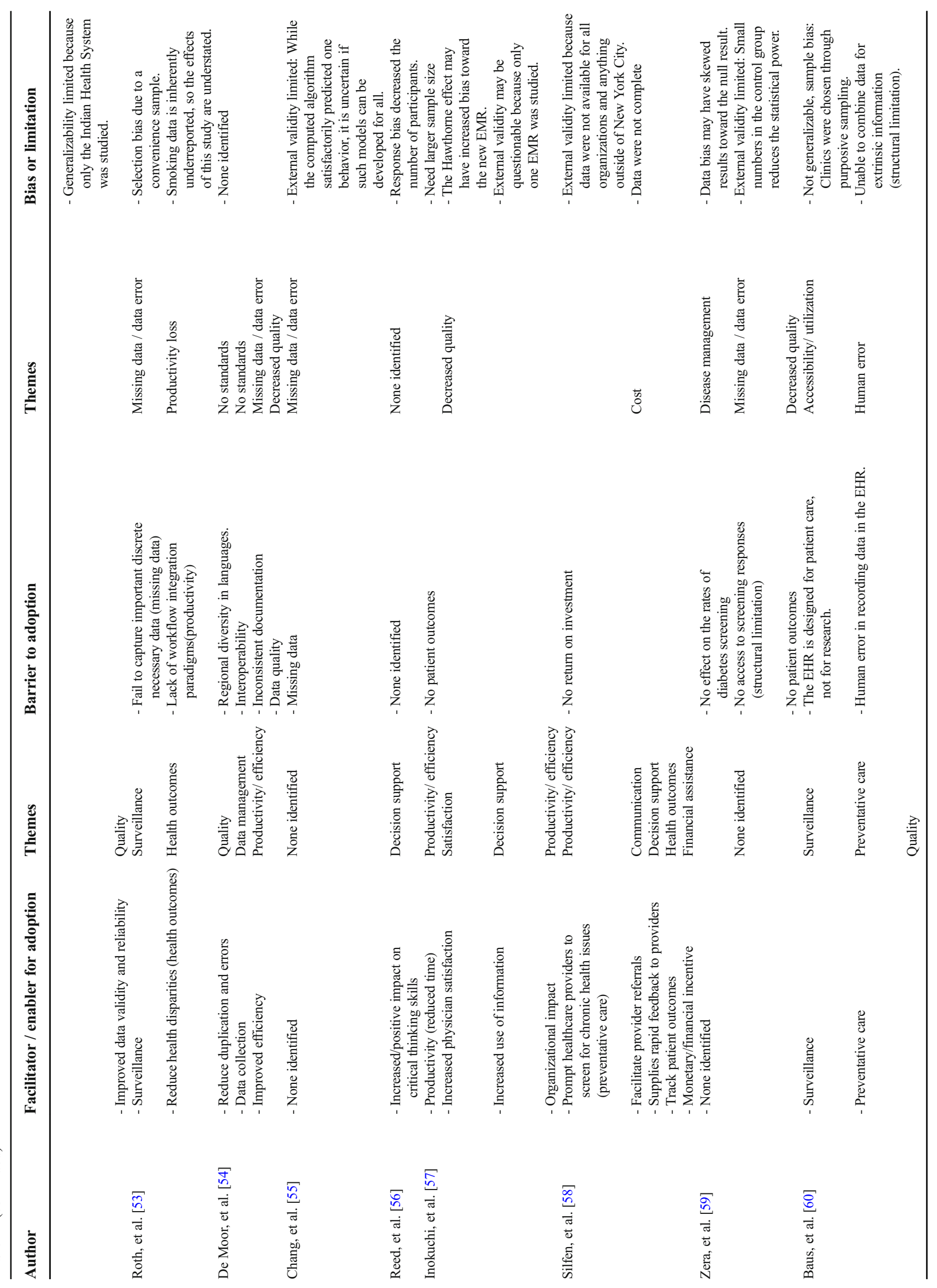




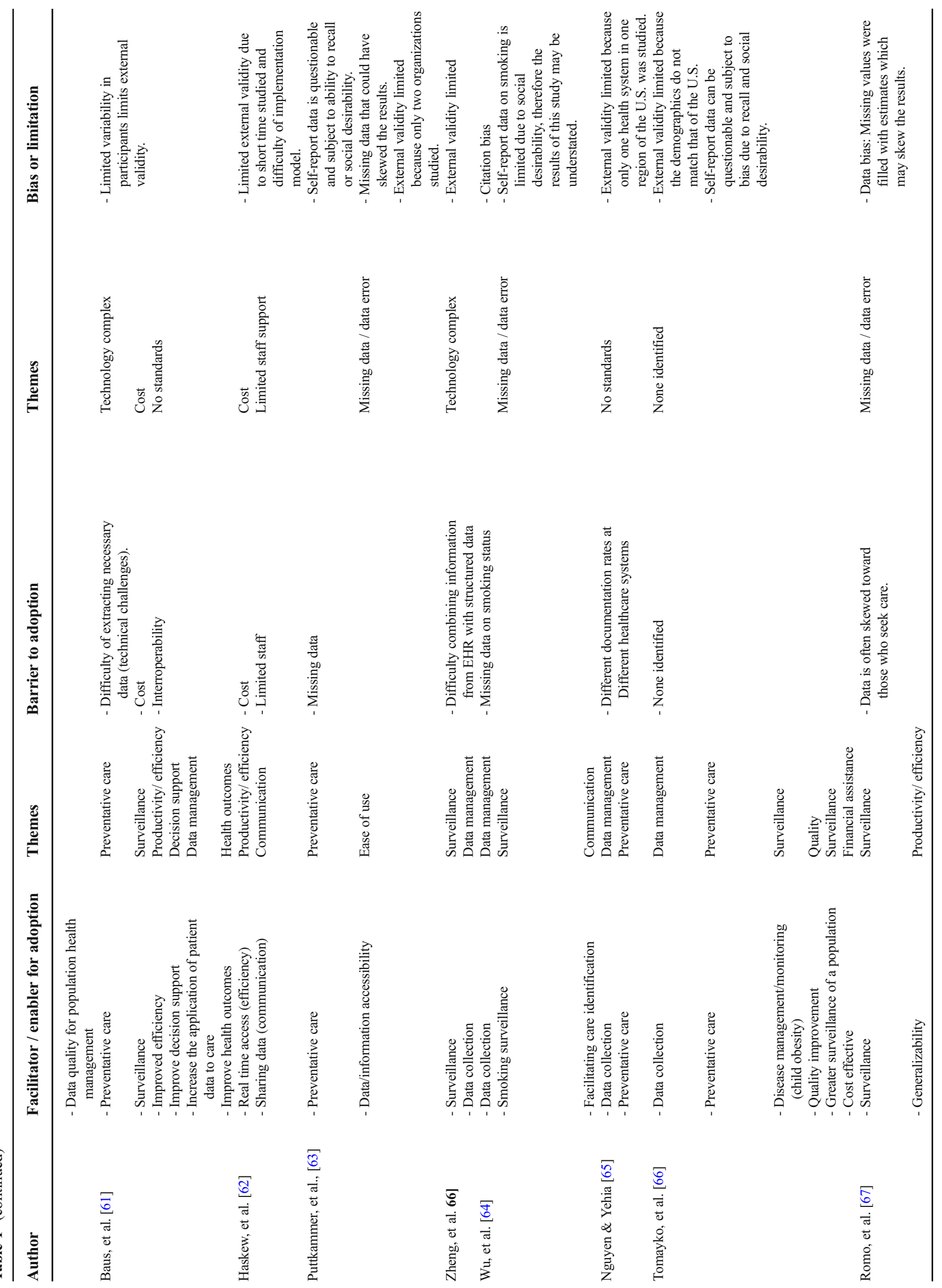




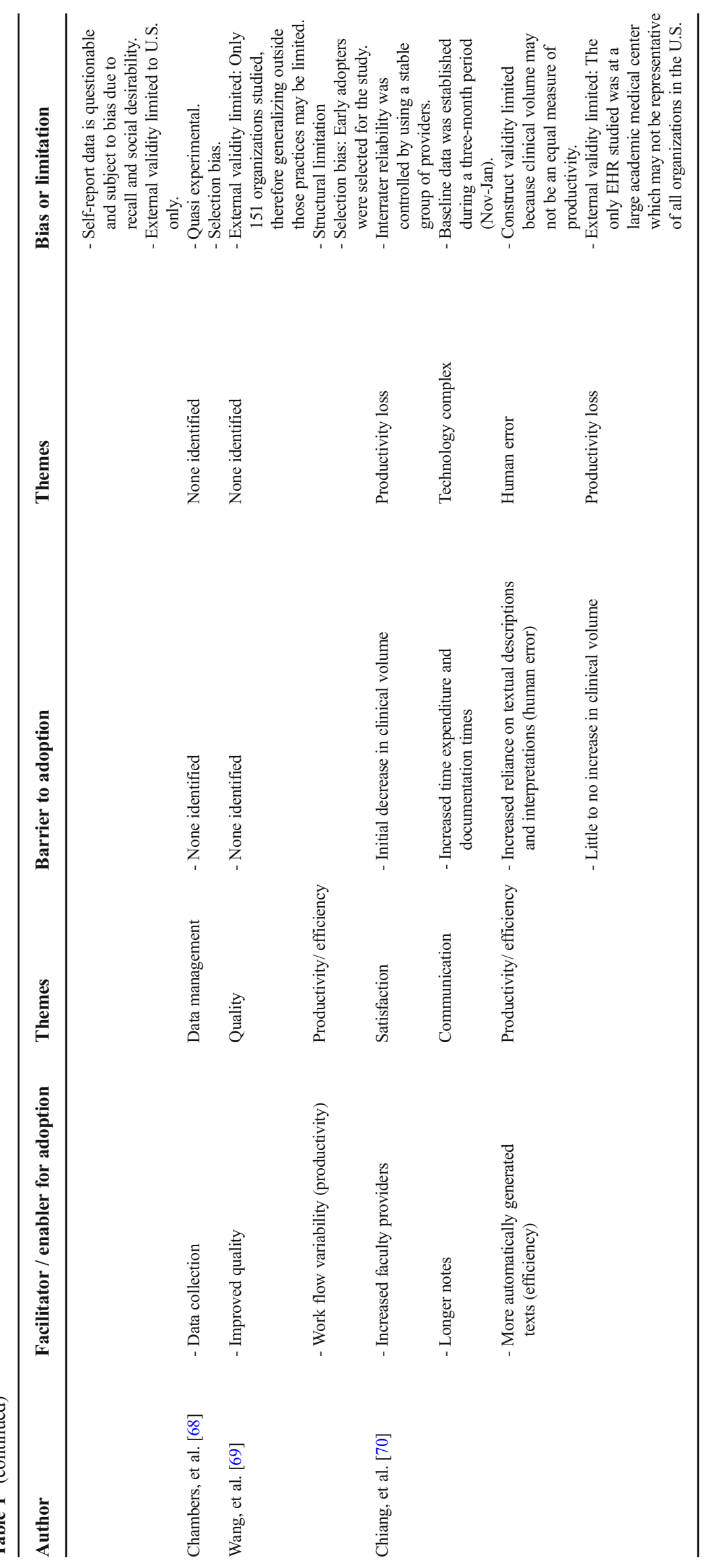


During the review process, various aspects of electronic health records showed that the utilization of these HIT improves population and public health. Benefits of using electronic medical records describe how EHRs improved the productivity and efficiency of health organizations to better serve populations. Increased healthcare access to individuals provides more comprehensive documentation from the population from the surveillance of public health screening and preventative care. Electronic health records allow health professionals to share and incorporate more public health information among various providers. This improves the population's ability to survey the populations for chronic disease, contagious infections, and allows for more rapid and uniform transference of patient information [7, 18-71]. The incorporation of new technology is expected to have some flaws associated with its integration into the healthcare field [7, 18-71]. Some of the major setbacks of EHRs and EMRs include a temporary decrease in productivity, while staff and medial personal incorporate and train employees to use an entirely new system. Alongside with new operational systems medical efforts, lack of functionality, system failures, and simple resistance to change by providers can occur. These can have negative impacts on public health as missing or incorrect information can be transmitted for surveillance. Other barriers include the inability to generalize one healthcare organization's experience to others due to various types of EHRs and systems to the wide variety of populations and settings. Some healthcare populations have been found to be more accepting of EHRs while others have found it more difficult to incorporate them into a daily routine [1]. The authors were able to organize and examine these themes in the discussion section.

\section{Additional analysis}

Affinity matrices were created to further analyze facilitators and barriers. These matrices are illustrated in Table 2.

A visual representation of these factors can also be seen in fig. 2.

Thirteen facilitators and 13 barriers were identified. The occurrences of facilitators outweighed those of the barriers 3:2. Several facilitators and barriers were similar and were combined, for instance productivity and efficiency. Articles that mentioned both facilitators are marked in the tables with an asterisk. Facilitators identified are productivity/efficiency $\left[19,21,22,24,25,27,28,30^{*}, 32,33-36^{*}, 38,43,45-47^{*}, 51,53-\right.$ $56,59 *, 60,63,64,70,72,73]$, quality $[19 *, 20,22,24-$ $27,33,34,45,46,49,53,54,56,62,69,72]$,data management $[7$, 18-21, 26, 30, 33, 37-39, 41, 48, 54, 64-66, 68, 71], surveillance $\left[19,20,23,25,26,28,31,41,54,55,62,63,66,67,69^{*}, 70\right]$, preventative care $\left[19^{*}, 23,26,28,30,36,37,39,52,62,63,65,68,69\right]$, communication [30, 36, 47, 50, 58, 62, 64, 70], interoperability [7, 19, 23, 31, 41, 43, 47, 49], decision support [7, 19, 34, 56-58, $61]$, health outcomes $[25,26,44,53,58,61]$, satisfaction $[32,33$,

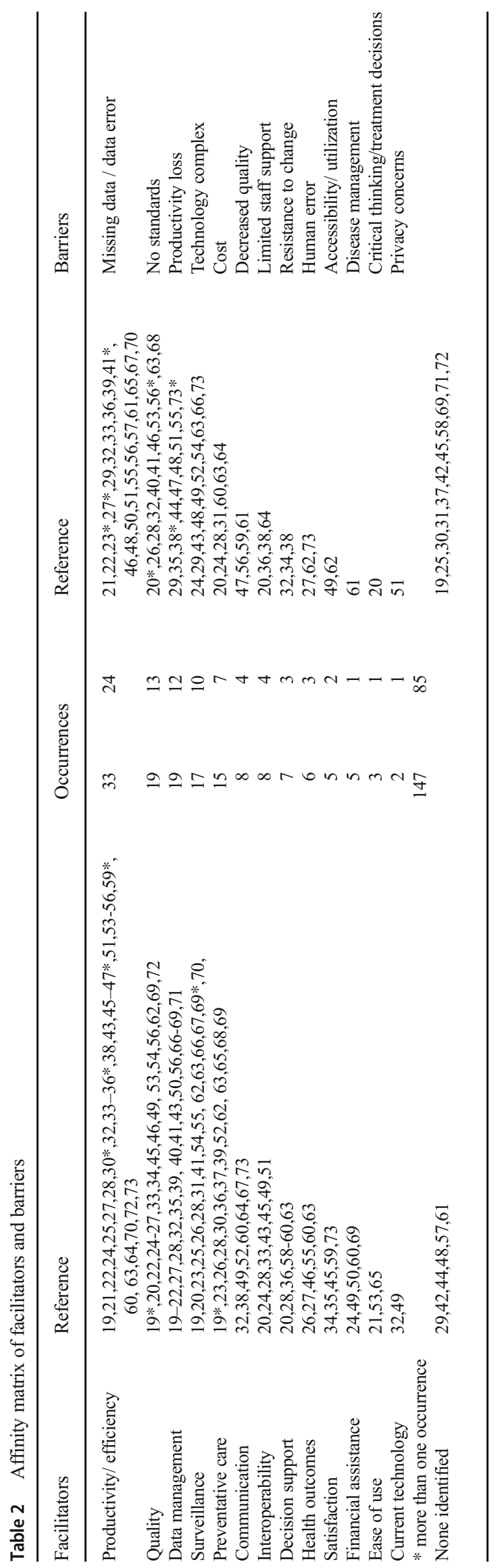


Facilitators

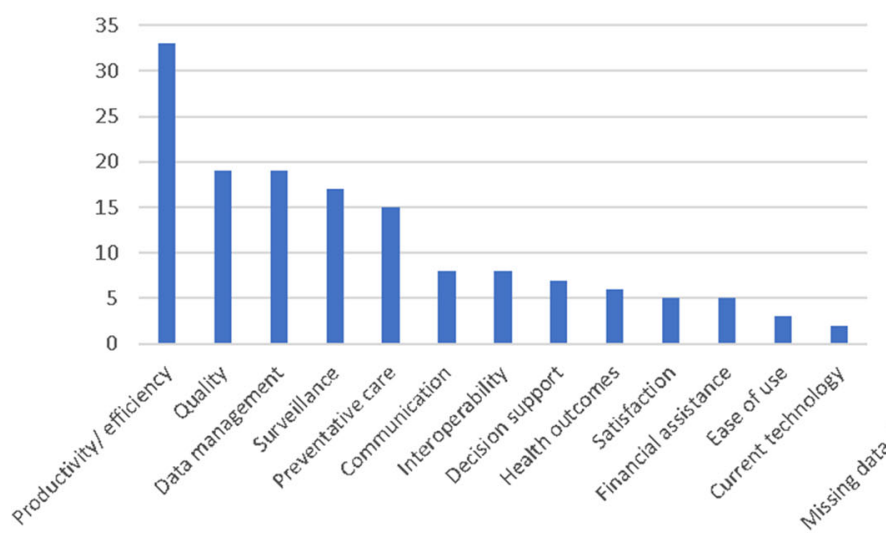

Fig. 2 Charts of the frequency of facilitators and barriers

43, 57, 70], financial assistance [23, 47, 48, 58, 66], ease of use [20, 51, 63], and current technology [30, 47], Barriers identified a re missing data/data error [21$\left.23^{*}, 27^{*}, 29,32,33,36,39,41^{*}, 46,48,50,51,55-57,61,65,67,70\right]$, no standards (of data or interoperability) $\left[20^{*}, 26,28,32,40,41,46,53,56^{*}, 63,68\right]$, productivity loss $\left[29,35,38^{*}, 44,47,48,51,55,73^{*}\right]$, technology (too) complex [23, $27,41,46,47,50,52,61,70,71]$, cost $[7,19,23,29,58,61$, 62],decreased quality (of data or care) $[45,54,57,59]$, limited staff support [19, 34, 36, 62], resistance to change [30, 32, 36], human error [26, 60, 70], accessibility/utilization [47, 60], disease management [59], critical thinking/treatment decisions [19], privacy concerns [49]. The top five facilitators and top four barriers make up about $70 \%$ of the factors observed.

\section{Discussion}

\section{Summary of evidence}

In this systematic review the authors reviewed 55 articles. The analysis identified 13 facilitators and 13 barriers, and facilitators outweighed barriers $3: 2$. The top three facilitators were an increase in productivity/efficiency (greater capacity, more efficient procedures and processes, etc.), an increase in the quality of data or care (data that was more accurate, more precise, and contained less error; care that produced higher quality outcomes as a result of more accurate data), and various aspects of data management (users were able to access patient data in a more efficient manner). The top three barriers were missing data (some data was missing or was not filled in) / data error (incorrect data was entered), no standards for interoperability (data could not easily be shared between providers), and a loss of productivity (teaching users how to use the EHR and dataentry requirements were time consuming and took users away from other duties in the office, which made the office less productive). The results of this review show more positive
Barriers

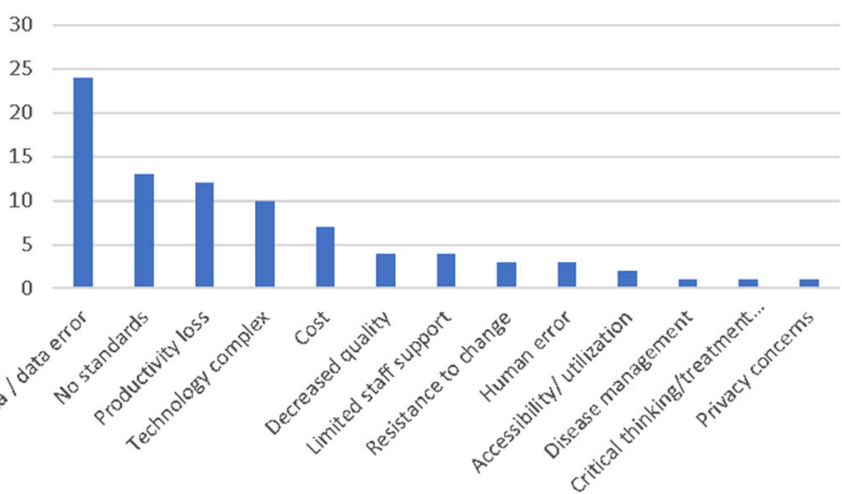

than negative factors for the use of the EHR to manage public health and surveillance.

The facilitator most often found in the literature is the increase of either productivity, efficiency, or both. Organizations were maximized time with patients instead of writing documentation. These articles said that EHRs improved the workflow in organizations. Other organizations identified a loss in productivity for the same reason. This could have been due to the stage of implementation in which the organizations were.

With the ability to access a greater number of records in a more productive way, it was not surprising that surveillance accounted for the third most recorded facilitator. Surveillance can utilize information from EHRs to make population and public health predictions as well as track occurrences of infectious diseases and other public health functions to have a better overall review of a population's health.

\section{Limitations}

To control for selection bias, reviewers agreed on definitions and concepts prior to the search and analysis of articles. Each article was reviewed and analyzed by multiple reviewers. A series of consensus meetings was held to share observations and agree on next steps. The team calculated a Kappa statistic of 0.83 which in fact shows a high level of agreement.

Publication bias is likely to occur because publishers tend to publish articles with significant relationships, and therefore articles that did not result in significant findings were not able to be selected for this review [72]. Our search was limited to PubMed and CINAHL, which may have impacted the scope of our results. These databases were chosen for their comprehensive scope and positive reputation in research.

\section{Comparison to other research}

Contrary to studies on the adoption of the EHR, the authors found that cost was not as prevalent a barrier in using EHRs in 
support of public health. This could be a result of sufficient time passing for financial incentives to alleviate the concern. The articles reviewed intimated that EHRs were cost effective, enhance productivity/efficiency and quality, and they are conducive for data collection when missing data is analyzed. Standards for interoperability need to continue to progress: Until all EHR solutions reach the same level of interoperability, data sharing cannot be assured.

\section{Conclusion}

Additional research should follow from this review. Productivity was both a facilitator and a barrier. It would be interesting to know if the latter is during implementation and the former is after. As nationwide adoption of a fully interoperable EHR progresses, many barriers identified in this review such as standards, and resistance to change could be mitigated. As more data becomes available through the EHR, relationships to outcomes should appear. Appropriate training on EHRs use, may help with the level of complexity among health care providers and their staff.

The EHR can improve health care productivity and efficiency to better serve public health. An abundance of health care information can be managed through databases by using electronic medical records, and this makes data more easily shared between providers and organizations.

\section{Compliance with ethical standards}

Conflicts of interest The authors declare that they have no conflict of interest.

Ethical approval For this type of review, formal consent is not required. This article does not contain any studies with human participants or animals performed by any of the authors.

Open Access This article is distributed under the terms of the Creative Commons Attribution 4.0 International License (http:// creativecommons.org/licenses/by/4.0/), which permits unrestricted use, distribution, and reproduction in any medium, provided you give appropriate credit to the original author(s) and the source, provide a link to the Creative Commons license, and indicate if changes were made.

\section{References}

1. Wager, K. A., Lee, F. W., Glaser, J. P., Health care information systems: a practical approach for health care management. John Wiley \& Sons; Mar 27, 2017.

2. U.S Department of Health and Human Services URL: https://www. healthit.gov/providers-professionals/faqs/what-electronic-healthrecord-ehr. Accessed: 2017-10-03. (Archived by WebCite ${ }^{\circledR}$ at http://www.webcitation.org/6twtffZwS)
3. Orlova, A., and Salyards, K., Understanding Information in EHR Systems: Paving the Road for Semantic Interoperability through Standards. Journal of AHIMA. 87(9):44 47, Sep 2016.

4. Kindig, D., and Stoddart, G., What is population health? American Journal of Public Health. 93(3):380-383, 2003 Mar.

5. Diamond, C. C., Mostashari, F., and Shirky, C., Collecting and sharing data for population health: a new paradigm. Health Affairs. 28(2):454 466, 2009 Mar 1.

6. Public health surveillance. World Health Organization. URL: http:// www.who.int/topics/public health surveillance/en/. Accessed: 2018-01-03. (Archived by WebCite® at http://www.webcitation. org/6wCf3xH19)

7. Calman, N., Hauser, D., Lurio, J., Wu, W. Y., and Pichardo, M., Strengthening public health and primary care collaboration through electronic health records. American Journal of Public Health. 102(11):e13-e18, 2012 Nov.

8. Paul, M. M., Greene, C. M., Newton-Dame, R., Thorpe, L. E., Perlman, S. E., McVeigh, K. H., and Gourevitch, M. N., The state of population health surveillance using electronic health records: a narrative review. Population Health Management. 18(3):209-216, 2015 Jun 1.

9. De Leon, S. F., and Shih, S. C., Tracking the delivery of preventionoriented care among primary care providers who have adopted electronic health records. Journal of the American Medical Informatics Association. 18(Supplement_1):i91-i95, 2011 Aug 19.

10. Flatow, V. H., Ibragimova, N., Divino, C. M., Eshak, D. S., Twohig, B. C., Bassily-Marcus, A. M., and Kohli-Seth, R., Quality outcomes in the surgical intensive care unit after electronic health record implementation. Applied Clinical Informatics. 6(04):611-618, 2015 Apr.

11. Tharmalingam, S., Hagens, S., and Zelmer, J., The value of connected health information: perceptions of electronic health record users in Canada. BMC Medical Informatics and Decision Making. 16(1):93, 2016 Jul 16.

12. Rinner, C., Sauter, S. K., Endel, G., Heinze, G., Thurner, S., Klimek, P., and Duftschmid, G., Improving the informational continuity of care in diabetes mellitus treatment with a nationwide Shared EHR system: Estimates from Austrian claims data. International Journal of Medical Informatics. 92:44-53, 2016 Aug 31 .

13. Ben-Assuli, O., Ziv, A., Sagi, D., Ironi, A., and Leshno, M., Costeffectiveness evaluation of EHR: simulation of an abdominal aortic aneurysm in the emergency department. Journal of Medical Systems. 40(6):141, 2016 Jun 1.

14. Beresniak, A., Schmidt, A., Proeve, J., Bolanos, E., Patel, N., Ammour, N., Sundgren, M., Ericson, M., Karakoyun, T., Coorevits, P., and Kalra, D., Cost-benefit assessment of using electronic health records data for clinical research versus current practices: Contribution of the Electronic Health Records for Clinical Research (EHR4CR) European Project. Contemporary Clinical Trials. 46:85-91, 2016 Jan 31.

15. Chan, K. S., Fowles, J. B., and Weiner, J. P., Electronic health records and the reliability and validity of quality measures: a review of the literature. Medical Care Research and Review. 67(5):503527, 2010 Oct.

16. Yanamadala, S., Morrison, D., Curtin, C., McDonald, K., Hernandez-Boussard, T., Electronic health records and quality of care: An observational study modeling impact on mortality, readmissions, and complications. Medicine. May;95(19), 2016.

17. Al-Jafar, E., Exploring patient satisfaction before and after electronic health record (EHR) implementation: the Kuwait experience. Perspectives in Health Information Management/AHIMA, American Health Information Management Association; 10(Spring), 2013.

18. Bailey, S. R., Marino, M., Hoopes, M., Heintzman, J., Gold, R., Angier, H., O’Malley, J. P., and DeVoe, J. E., Healthcare Utilization 
After a Children's Health Insurance Program Expansion in Oregon. Maternal and Child Health Journal. 20(5):946-954, 2016 May 1.

19. Houser, S. H., Colquitt, S., Clements, K., Hart-Hester, S., The impact of electronic health record usage on cancer registry systems in Alabama. Perspectives in Health Information Management/ AHIMA, American Health Information Management Association. 9(Spring), 2012.

20. Metroka, A. E., Papadouka, V., Ternier, A., and Zucker, J. R., Effects of Health Level 7 Messaging on Data Quality in New York City's Immunization Information System, 2014. Public Health Reports. 131(4):583-587, 2016 Jul.

21. Blecker, S., Goldfeld, K., Park, N., Shine, D., Austrian, J. S., Braithwaite, R. S., Radford, M. J., and Gourevitch, M. N., Electronic health record use, intensity of hospital care, and patient outcomes. The American Journal of Medicine. 127(3):216-221, 2014 Mar 31.

22. Flood, T. L., Zhao, Y. Q., Tomayko, E. J., Tandias, A., Carrel, A. L., and Hanrahan, L. P., Electronic health records and community health surveillance of childhood obesity. American Journal of Preventive Medicine. 48(2):234-240, 2015 Feb 28.

23. Martelle, M., Farber, B., Stazesky, R., Dickey, N., Parsons, A., Venters, H., Meaningful Use of an Electronic Health Record in the New York City Jail System. Journal Information. Sep;105(9), 2015.

24. Chambers, E. C., Wong, B. C., Riley, R. W., Hollingsworth, N., Blank, A. E., Myers, C., Bedell, J., Selwyn, P. A., Combining clinical and population-level data to understand the health of neighborhoods. American Journal of Public Health (AJPH). Mar 3, 2015.

25. Moody-Thomas, S., Nasuti, L., Yi, Y., Celestin, Jr., M. D., Horswell, R., and Land, T. G., Effect of systems change and use of electronic health records on quit rates among tobacco users in a public hospital system. American Journal of Public Health. 105(S2):e1-e7, 2015 Apr.

26. Vogel, J., Brown, J. S., Land, T., Platt, R., and Klompas, M., MDPHnet: secure, distributed sharing of electronic health record data for public health surveillance, evaluation, and planning. American Journal of Public Health. 104(12):2265-2270, 2014 Dec.

27. Duan, R., Cao, M., Wu, Y., Huang, J., Denny, J. C., Xu, H., Chen, Y., An Empirical Study for Impacts of Measurement Errors on EHR based Association Studies. In AMIA Annual Symposium Proceedings (Vol. 2016, p. 1764). American Medical Informatics Association, 2016.

28. Kawamoto, K., Anstrom, K. J., Anderson, J. B., Bosworth, H. B., Lobach, D. F., McAdam-Marx, C., Ferranti, J. M., Shang, H., Yarnall, K. S., Long-Term Impact of an Electronic Health RecordEnabled, Team-Based, and Scalable Population Health Strategy Based on the Chronic Care Model. In AMIA Annual Symposium Proceedings 2016 (Vol. 2016, p. 686). American Medical Informatics Association.

29. Behrens, J. J., Wen, X., Goel, S., Zhou, J., Fu, L., Kho, A. N., Using Monte Carlo/Gaussian Based Small Area Estimates to Predict Where Medicaid Patients Reside. In AMIA Annual Symposium Proceedings 2016 (Vol. 2016, p. 305). American Medical Informatics Association.

30. Cross, D. A., Cohen, G.R., Nong, P., Day, A.V., Vibbert, D., Naraharisetti, R., Adler-Milstein, J., Improving EHR Capabilities to Facilitate Stage 3 Meaningful Use Care Coordination Criteria. In AMIA Annual Symposium Proceedings 2015 (Vol. 2015, p. 448). American Medical Informatics Association.

31. Tanner, C., Gans, D., White, J., Nath, R., and Pohl, J., Electronic health records and patient safety: co-occurrence of early EHR implementation with patient safety practices in primary care settings. Applied Clinical Informatics. 6(1):136, 2015.

32. Emani, S., Ting, D. Y., Healey, M., Lipsitz, S. R., Karson, A. S., Einbinder, J. S., Leinen, L., Suric, V., and Bates, D. W., Physician beliefs about the impact of meaningful use of the EHR: a crosssectional study. Applied Clinical Informatics. 5(3):789-801, 2014.

33. Benkert, R., Dennehy, P., White, J., Hamilton, A., Tanner, C., and Pohl, J. M., Diabetes and hypertension quality measurement in four safety-net sites: lessons learned after implementation of the same commercial electronic health record. Applied Clinical Informatics. 5(3):757-772, 2014.

34. Merrill, J., Phillips, A., Keeling, J., Kaushal, R., and Senathirajah, Y., Effects of automated immunization registry reporting via an electronic health record deployed in community practice settings. Applied Clinical Informatics. 4(2):267, 2013.

35. Glicksberg, B. S., Li, L., Badgeley, M. A., Shameer, K., Kosoy, R., Beckmann, N. D., Pho, N., Hakenberg, J., Ma, M., Ayers, K. L., and Hoffman, G. E., Comparative analyses of population-scale phenomic data in electronic medical records reveal race-specific disease networks. Bioinformatics. 32(12):i101-i110, 2016 Jun 11.

36. McAlearney, A. S., Sieck, C., Hefner, J., Robbins, J., and Huerta, T. R., Facilitating ambulatory electronic health record system implementation: evidence from a qualitative study. Biomed Research International. 20:2013, 2013 Oct.

37. Polling, C., Tulloch, A., Banerjee, S., Cross, S., Dutta, R., Wood, D. M., Dargan, P. I., and Hotopf, M., Using routine clinical and administrative data to produce a dataset of attendances at Emergency Departments following self-harm. BMC Emergency Medicine. 15(1):15, 2015 Jul 16.

38. Zhao, J., Henriksson, A., Asker, L., and Boström, H., Predictive modeling of structured electronic health records for adverse drug event detection. BMC Medical Informatics and Decision Making. 15(4):S1, 2015 Nov 25.

39. Roth, C., Foraker, R. E., Payne, P. R., and Embi, P. J., Communitylevel determinants of obesity: harnessing the power of electronic health records for retrospective data analysis. BMC Medical Informatics and Decision Making. 14(1):36, 2014 May 8.

40. Barnett, M. L., Mehrotra, A., and Jena, A. B., Adverse inpatient outcomes during the transition to a new electronic health record system: observational study. BMJ. 354:i3835, 2016 Jul 28.

41. Drawz, P. E., Archdeacon, P., McDonald, C. J., Powe, N. R., Smith, K. A., Norton, J., Williams, D. E., Patel, U. D., Narva, A., CKD as a model for improving chronic disease care through electronic health records. Clinical Journal of the American Society of Nephrology. Jun 25:CJN-0e0940115, 2015.

42. Thirukumaran, C. P., Dolan, J. G., Webster, P. R., Panzer, R. J., and Friedman, B., The impact of electronic health record implementation and use on performance of the Surgical Care Improvement Project measures. Health Services Research. 50(1):273-289, 2015 Feb 1.

43. Adler-Milstein, J., Everson, J., and Lee, S. Y., EHR Adoption and Hospital Performance: Time-Related Effects. Health Services Research. 50(6):1751-1771, 2015 Dec 1.

44. Ananthakrishnan, A. N., Cagan, A., Cai, T., Gainer, V. S., Shaw, S. Y., Savova, G., Churchill, S., Karlson, E. W., Murphy, S. N., Liao, K. P., and Kohane, I., Identification of nonresponse to treatment using narrative data in an electronic health record inflammatory bowel disease cohort. Inflammatory Bowel Diseases. 22(1):151158, 2015 Aug 31.

45. Carayon, P., Wetterneck, T. B., Alyousef, B., Brown, R. L., Cartmill, R. S., McGuire, K., Hoonakker, P. L., Slagle, J., Van Roy, K. S., Walker, J. M., and Weinger, M. B., Impact of electronic health record technology on the work and workflow of physicians in the intensive care unit. International Journal of Medical Informatics. 84(8):578-594, 2015 Aug 31.

46. Redd, T. K., Read-Brown, S., Choi, D., Yackel, T. R., Tu, D. C., and Chiang, M. F., Electronic health record impact on productivity and efficiency in an academic pediatric ophthalmology practice. Journal of American Association for Pediatric Ophthalmology and Strabismus. 18(6):584-589, 2014 Dec 31. 
47. Jones, E., and Wittie, M., Accelerated adoption of advanced health information technology in Beacon community health centers. The Journal of the American Board of Family Medicine. 28(5):565575, 2015 Sep 1.

48. Hammermeister, K., Bronsert, M., Henderson, W. G., Coombs, L., Hosokawa, P., Brandt, E., Bryan, C., Valuck, R., West, D., Liaw, W., and Ho, M., Risk-adjusted comparison of blood pressure and low-density lipoprotein (LDL) noncontrol in primary care offices. The Journal of the American Board of Family Medicine. 26(6): 658-668, 2013 Nov 1.

49. Benson, G. A., Sidebottom, A., VanWormer, J. J., Boucher, J. L., Stephens, C., and Krikava, J., HeartBeat Connections: a rural community of solution for cardiovascular health. The Journal of the American Board of Family Medicine. 26(3):299-310, 2013 May 1.

50. Soulakis, N. D., Carson, M. B., Lee, Y. J., Schneider, D. H., Skeehan, C. T., and Scholtens, D. M., Visualizing collaborative electronic health record usage for hospitalized patients with heart failure. Journal of the American Medical Informatics Association. 22(2):299-311, 2015 Feb 20.

51. Burke, H. B., Sessums, L. L., Hoang, A., Becher, D. A., Fontelo, P., Liu, F., Stephens, M., Pangaro, L. N., O'malley, P. G., Baxi, N. S., and Bunt, C. W., Electronic health records improve clinical note quality. Journal of the American Medical Informatics Association. 22(1):199-205, 2014 Oct 23.

52. Keck, J. W., Redd, J. T., Cheek, J. E., Layne, L. J., Groom, A. V., Kitka, S., Bruce, M. G., Suryaprasad, A., Amerson, N. L., Cullen, T., and Bryan, R. T., Influenza surveillance using electronic health records in the American Indian and Alaska Native population. Journal of the American Medical Informatics Association. 21(1): 132-138, 2013 Jun 5.

53. Roth, C., Payne, P. R., Weier, R. C., Shoben, A. B., Fletcher, E. N., Lai, A. M., Kelley, M. M., Plascak, J. J., and Foraker, R. E., The geographic distribution of cardiovascular health in the stroke prevention in healthcare delivery environments (SPHERE) study. Journal of Biomedical Informatics. 60:95-103, 2016 Apr 30.

54. De Moor G, Sundgren M, Kalra D, Schmidt A, Dugas M, Claerhout B, Karakoyun T, Ohmann C, Lastic PY, Ammour N, Kush R. Using electronic health records for clinical research: the case of the EHR4CR project. Journal of Biomedical Informatics. 2015 Feb 28;53:162-173.

55. Chang, N. W., Dai, H. J., Jonnagaddala, J., Chen, C. W., Tsai, R. T., and Hsu, W. L., A context-aware approach for progression tracking of medical concepts in electronic medical records. Journal of Biomedical Informatics. 58:S150-S157, 2015 Dec 31.

56. Reed, S. G., Adibi, S. S., Coover, M., Gellin, R. G., Wahlquist, A. E., AbdulRahiman, A., Hamil, L. H., Walji, M. F., O'Neill, P., and Kalenderian, E., Does Use of an Electronic Health Record with Dental Diagnostic System Terminology Promote Dental Students' Critical Thinking? Journal of Dental Education. 79(6):686-696, 2015 Jun 1.

57. Inokuchi, R., Sato, H., Iwagami, M., Komaru, Y., Iwai, S., Gunshin, M., Nakamura, K., Shinohara, K., Kitsuta, Y., Nakajima, S., Yahagi, N., Impact of a New Medical Record System for Emergency Departments Designed to Accelerate Clinical Documentation: A Crossover Study. Medicine. Jul;94(26), 2015.

58. Silfen, S. L., Farley, S. M., Shih, S. C., Duquaine, D. C., Ricci, J. M., Kansagra, S. M., Edwards, S. M., Babb, S., and McAfee, T., Increases in smoking cessation interventions after a feedback and improvement initiative using electronic health records - 19 community health centers, New York City, October 2010March 2012. MMWR Morb Mortal Wkly Rep 63(41):921-924, 2014 Oct 17

59. Zera, C. A., Bates, D. W., Stuebe, A. M., Ecker, J. L., and Seely, E. W., Diabetes screening reminder for women with prior gestational diabetes: a randomized controlled trial. Obstetrics and Gynecology. 126(1):109, 2015 Jul.

60. Baus, A., Zullig, K., Long, D., Mullett, C., Pollard, C., Taylor, H., Coben, J., Developing methods of repurposing electronic health record data for identification of older adults at risk of unintentional falls. Perspectives in Health Information Management.;13(Spring), 2016.

61. Baus, A., Wood, G., Pollard, C., Summerfield, B., White, E., Registry-based diabetes risk detection schema for the systematic identification of patients at risk for diabetes in West Virginia primary care centers. Perspectives in Health Information Management; 10(Fall), 2013.

62. Haskew, J., Rø, G., Turner, K., Kimanga, D., Sirengo, M., and Sharif, S., Implementation of a cloud-based electronic medical record to reduce gaps in the HIV treatment continuum in rural Kenya. PloS One. 10(8):e0135361, 2015 Aug 7.

63. Puttkammer, N., Zeliadt, S., Balan, J. G., Baseman, J., Destine, R., Domerçant, J. W., France, G., Hyppolite, N., Pelletier, V., Raphael, N. A., and Sherr, K., Development of an electronic medical record based alert for risk of HIV treatment failure in a low-resource setting. PloS One. 9(11):e112261, 2014 Nov 12.

64. Wu, C. Y., Chang, C. K., Robson, D., Jackson, R., Chen, S. J., Hayes, R. D., and Stewart, R., Evaluation of smoking status identification using electronic health records and open-text information in a large mental health case register. PloS One. 8(9):e74262, 2013 Sep 12.

65. Nguyen, G. T., and Yehia, B. R., Documentation of Sexual Partner Gender Is Low in Electronic Health Records: Observations, Predictors, and Recommendations to Improve Population Health Management in Primary Care. Population Health Management. 18(3):217-222, 2015 Jun 1.

66. Tomayko, E. J., Weinert, B. A., Godfrey, L., Adams, A. K., Hanrahan, L. P., Peer Reviewed: Using Electronic Health Records to Examine Disease Risk in Small Populations: Obesity Among American Indian Children, Wisconsin, 2007-2012. Preventing Chronic Disease. 13, 2016.

67. Romo, M. L., Chan, P. Y., Lurie-Moroni, E., Perlman, S. E., Newton-Dame, R., Thorpe, L. E., McVeigh, K. H., Peer Reviewed: Characterizing Adults Receiving Primary Medical Care in New York City: Implications for Using Electronic Health Records for Chronic Disease Surveillance. Preventing Chronic Disease. 13, 2016.

68. Chambers, E. C., Wylie-Rosett, J., Blank, A. E., Ouziel, J., Hollingsworth, N., Riley, R. W., Selwyn, P. A., Peer Reviewed: Increasing Referrals to a YMCA-Based Diabetes Prevention Program: Effects of Electronic Referral System Modification and Provider Education in Federally Qualified Health Centers. Preventing Chronic Disease. 12, 2015.

69. Wang, J. J., Sebek, K. M., McCullough, C. M., Amirfar, S. J., Parsons, A. S., Singer, J., Shih, S. C., Peer reviewed: sustained improvement in clinical preventive service delivery among independent primary care practices after implementing electronic health record systems. Preventing Chronic Disease. 10, 2013.

70. Chiang, M. F., Read-Brown, S., Tu, D. C., Choi, D., Sanders, D. S., Hwang, T. S., Bailey, S., Karr, D. J., Cottle, E., Morrison, J. C., and Wilson, D. J., Evaluation of electronic health record implementation in ophthalmology at an academic medical center (an American Ophthalmological Society thesis). Transactions of the American Ophthalmological Society. 111:70, 2013 Sep.

71. Zheng, H., Gaff, H., Smith, G., and DeLisle, S., Epidemic surveillance using an electronic medical record: an empiric approach to performance improvement. PloS One. 9(7):e100845, 2014 Jul 9.

72. Hopewell, S., Loudon, K., Clarke, M. J., Oxman, A. D., Dickersin, K., Publication bias in clinical trials due to statistical significance or direction of trial results. The Cochrane Library. Jan 1, 2009. 